\title{
Influence of ionization and ion-pair formation on lipophilicity of some 4-hydroxycoumarin derivatives in the octanol-water system
}

\author{
Willem F. van der Giesen and Lambcrt H.M. Janssen \\ Department of Pharmaceutical Chemistry, Faculty of Pharmacy, University' of Utrecht, Catharijnesingel 60 , \\ 3511 GH Utrecht (The Netherlands)
}

(Received October 26th, 1981)

(Modified version received March 15th, 1982)

(Accepted April 5th, 1982)

\section{Summary}

The pH-dependent distribution of weak acids in the octanol-water system was investigated. For a series of six 4-hydroxycoumarins, substituted at position 3, the apparent partition coefficient or the distribution coefficient, $P_{a p p}$, was measured in the $\mathrm{pH}$ range $1-i 1$. The $\log \mathrm{P}_{\mathrm{app}}-\mathrm{pH}$ profiles obtained are in complete agreement with the theory. At high $\mathrm{pH}$ the value of $\mathrm{P}_{\mathrm{app}}$ is independent of $\mathrm{pH}$, but dependent on the concentration of counterions $\left(\mathrm{Na}^{+}\right.$in this study) in the aqueous phase; in other words ion-pair extraction occurs. The $\mathrm{pNa}\left(-\log \left[\mathrm{Na}^{+}\right]\right)$-dependent distribution is analogous to the pH-dependent distribution, except in the case of 4-hydroxycoumarin. Evidence was found that the sodium ion-pair of 4-hydroxycoumarin dissociates considerably in the octanol phase. A large discrepancy was noted between the experimentally obtained $\log \mathbf{P}$ values and the theoretical values calculated using the hydrophobic fragmental constant system. $\log P_{\text {app }}$ values obtained under conditions where the compounds are ionized in the aqueous phase depend on both the partition coefficient and the dissociation constant of the acid or salt. Partition coefficients of the sodium ion-pairs obtained by extrapolation are just slightly lower than the partition coefficients of the undissociated acids.

\section{Introduction}

Hansch and co-workers (Hansch et al., 1963, 1973) were the first to use the linear free-energy approach in studies concerning the quantitative structure-activity rela- 
tionships (QSAR) of biologically active compounds. It has become increasinf'y lear since then that the lipophilicity is often an important factor in determi.uing the extent of the biological activity of compounds. The partition coefficient is always used as a quantitative measure of lipophilicity, and is generally measured in the octanol-water system (Smith et al., 1975).

Many biologically active compounds are weak acids or bases and occur as ionized species at the pH of interest. It seems likely that the activities associatet with ionized and unionized forms will differ. This difference may be due to the different lipophilicity of the two forms. To obtain more insight into this problem one needs to -tudy the influence of ionization on the lipophilicity in more detail by exploring the effect of $\mathrm{pH}$ on the distribution process. In the relevant literature there are a number of studies (Ezumi and Kubota, 1980; Moser et al., 1975; Murthy and Zografi, 1970; Le Petit, 1977, 1980; Schaper, 1979, Tsuji et al., 1977; Unger and Feuerman, 1979; Vezin and Florence, 1979; Wang and Lien, 1980; Yalkowsky and Morozowick. 1980) dealing with the pH-dependent partitioning of protolytes, some of which are more detailed than others. In this literature one frequently encounters the assumption that the charged species of a molecule are not found in the organic phase. This assumption. however, should be viewed critically (Dearden and George, 1978). In this connection the possible occurrence of ion-pairs in the organic phase should be taken into consideration (Colaizzi and Klink, 1969; Dearden and veorge, 1978; Ezumi and Kubota, 1980; Irwin et al., 1969; Irwin and Li Wan Po, 1979; Murthy and Zografi. 1970; Terada et al., 1981).

For this paper we decided to investigate the $\mathrm{pH}$-dependent partitioning of some derivatives of 4hydroxycoumarin in the octanol-water system. It has been established in our laboratories that the binding of the 4-hydroxycoumarin anticoagulants to serum albumin is pH-dependent (Wilting et al., 1980, 1981) and it is known that hydrophobic forces often play an important role in protein binding. To obtain good insight into the pH-dependent albumin binding we need a full understanding of the pH-defendient lipophilicity of these compounds. Special attention is given to ion-pair formation.

\section{Theory}

For the acid HA the dissociation can be represented by:

$\mathrm{HA} \rightleftharpoons \mathrm{H}^{+}+\mathbf{A}^{-}$

and the corresponding dissociation constant as

$K_{a}=\frac{\left[H^{+}\right]_{w}\left[A^{-}\right]_{w}}{[H A]_{w}}$

The subscript $w$ indicates the water phase. The partition coefficient $P$ of the undissociated acid HA is defined according to: 
$\mathbf{P}_{\mathbf{H A}}=\frac{[\mathrm{HA}]_{0}}{[\mathrm{HA}]_{\mathbf{w}}}$

The subscript o indicates the organic phase. Symbols or concentrations without the subscript $w$ or $o$ are assumed to refer to the aqueous phase. Molar concentrations are used.

Depending on the experimental circumstances the acid HA may be found as several molecular species in both the aqueous and the organic phase. The apparent partition coefficient or distribution coefficient, $P_{a p p}$, is defined as the sum of the concentrations of all species of the acid in the organic phase, divided by the sum of the concentrations of all species in the aqueous phase.

When the partitioning process is represented by Scheme a in Fig. $1, P_{a p p}$ is given by:

$\mathbf{P}_{\mathrm{app}}=\frac{[\mathrm{HA}]_{0}}{[\mathrm{HA}]_{\mathrm{w}}+\left[\mathbf{A}^{-}\right]_{\mathrm{w}}}$

Combining Eqns. 2, 3 and 4 and transferring to log gives:

$\log \mathrm{P}_{\mathrm{aFP}}=\log \mathrm{P}_{\mathrm{HA}}-\mathrm{pH}-\log \left(\left[\mathrm{H}^{+}\right]+\mathrm{K}_{\mathrm{a}}\right)$

or, when $\alpha$ is the degree of dissociation of HA

$\log P_{\text {afP }}=\log P_{\mathrm{HA}}+\log (1-\alpha)$

It is clear that when $\mathrm{pH}=\mathrm{pK}_{\mathrm{a}}, \log \mathrm{P}_{\mathrm{a} p \mathrm{p}}=\log \mathrm{P}_{\mathrm{HA}}-0.301$. For certain $\mathrm{pH}$ regions Eqn. 5 can be replaced by a simpler equation. In the $\mathrm{pH}$ region where $\mathrm{pH} \ll \mathrm{pK}_{\mathrm{a}}$, or $\left[\mathrm{H}^{+}\right] \rightarrow \mathrm{K}_{\mathrm{a}}$, Eqn. 5 becomes:

$\log P_{\mathrm{app}}=\log \mathbf{P}_{\mathrm{HA}}$

Undc- these conditions $\log \mathrm{P}_{\mathrm{app}}$ is independent of $\mathrm{pH}$, and plotting $\log \mathrm{P}_{\mathrm{app}}$ against $\mathrm{pH}$ will yield a straight line with zero slope. In the $\mathrm{pH}$ region where $\mathrm{pH} \gg \mathrm{pK}_{\mathrm{a}}$, or

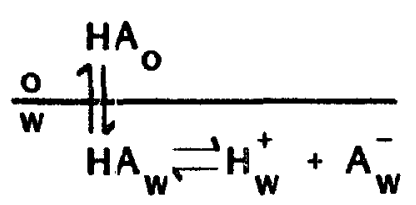

a

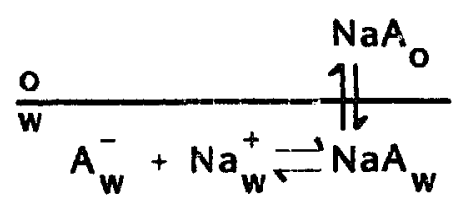

b

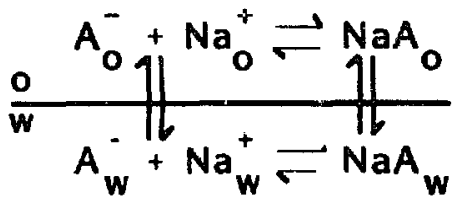

c

Fig. 1. Possible partition mechanisms of a weak acid, HA, between an aqueous phase (w) and an organic phase (o). a: pH not too far above $\mathrm{pK}_{\mathrm{a}}$; b: pH far above $\mathrm{pK}_{\mathrm{a}}$; $\mathrm{c:}$ pH far above $\mathrm{pK}_{\mathrm{a}}$ and including dissociation of the ion-pair in the organic phase. 
$\left[\mathrm{H}^{+}\right] \ll \mathrm{K}$. Eqn. 5 becomes:

$\log \mathrm{P}_{\mathrm{app}}=\log \mathrm{P}_{\mathrm{HA}}-\mathrm{pH}+\mathrm{pK}$

Plotting $\log \mathrm{P}_{\mathrm{app}}$ against the $\mathrm{pH}$ results in a straight line with a slope value of -1 . The straight lines given by Eqns. 7 and 8 intersect at $\mathrm{pH}=\mathrm{pK}_{\mathrm{a}}$. This means that if one is able to measure the partitioning of a substance in the pH region where Eqn. 7 is valid, the $\log P_{H A}$ can be found directly. If, in addition, the partitioning is known in the $\mathrm{pH}$ region where Eqn. 8 is valid, then one can find the $\mathrm{pK}_{\mathrm{a}}$ value or, if the $\mathrm{pK}_{\mathrm{a}}$ value is already known from another source, the partition $\mathrm{pH}$ profile can be checked. If only the distribution has been studied in the pH region where Eqn. 8 is valid, then the $\log \mathbf{P}_{\mathrm{HA}}$ can be estimated by extrapolating, provided the $\mathrm{pK}_{\mathrm{a}}$ value is known.

The use of Eqn. 7 instead of the full expression as given in Eqn. 5 or Eqn. 6 is allowed when $\mathrm{pH}<\mathrm{pK}_{\mathrm{a}}-1.5$, because then the value of $\log (1-\alpha)$ is less than 0.013. The accuracy of $\log P_{a p p}$ values obtained experimentally is certainly not better than 0.01 , so it reasonable to use Eqn. 7 in the pH region, as stated above. On similar grounds it can be demonstrated that Eqn. 8 can be used at $\mathrm{pH}>\mathrm{pK}_{\mathrm{a}}+1.5$.

In the region $\mathrm{pK}_{\mathrm{a}}-1.5<\mathrm{pH}<\mathrm{pK}_{\mathrm{a}}+1.5$ none of the terms in Eqn. 5 can be ignored, so the full equation must be used. This equation can be written as

$\mathbf{P}_{\mathrm{app}}^{-1}=\mathbf{P}_{\mathbf{H A}}^{-1}+\mathbf{K}_{\mathrm{a}} \cdot \mathbf{P}_{\mathbf{H A}}^{-1} \cdot\left[\mathbf{H}^{+}\right]^{-1}$

Plotting $\mathbf{P}_{\text {app }}^{-1}$ against $\left[\mathrm{H}^{+}\right]^{-1}$ results in a straight line with intercept $\mathbf{P}_{\mathrm{HA}}^{-1}$ and slope $K_{a} \cdot P_{H A}^{-1}$. At first glance Eqn. 9 seems to be very suitable for determining $K_{a}$ and $P_{H A}$ values simultaneously (Ezumi and Kubota, 1980). However, one should realize that this method can only be used if the $\mathrm{pH}$ is in region of $\mathrm{pK}_{\mathrm{a}}-1.5<\mathrm{pH}<\mathrm{pK}_{\mathrm{a}}+$ 1.5.

At relatively high $\mathrm{pH}$ values $[\mathrm{HA}]_{\mathrm{w}}$ becomes very small compared to $\left[\mathrm{A}^{-}\right]_{\mathrm{w}}$ and partitioning of the anion should be taken into account as well. The partitioning process can now be represented by Scheme $b$ in Fig. 1. Due to the fact that electroneutrality in each phase must be maintained, ions can pass to the other phase cnly if they are accompanied by an equivalent amount of ions of opposite charge. In other words ion-pair extraction occurs. This model for the partitioning of entirely ionized compounds is widely accepted in the theory of ion-pair extraction and in ion-pair liquid-liquid chromatography (Schill, 1978).

At sufficiently high $\mathrm{pH}$ and when only $\mathrm{H}^{+}$and $\mathrm{Na}^{+}$are present as cations, $\mathrm{P}_{\mathrm{app}}$ is given by:

$\mathbf{P}_{\mathrm{app}}=\frac{[\mathrm{NaA}]_{0}}{\left[\mathrm{~A}^{-}\right]_{\mathrm{w}}}$

This implies that the $\log \mathrm{P}_{\text {app }}-\mathrm{pH}$ profile reaches a constant level at high $\mathrm{pH}$, provided the counterion concentration is kept constant. Of course there will be a gradual change from the situation described by Eqn. 8 to the situation described by 
Eqn. 10. This means that Scheme a and Scheme b in Fig. 1 represent two extreme situations.

The model represented by Scheme b in Fig. 1 can be described in a similar way as the model of Scheme a if we introduce the term $\mathbf{P}_{\mathrm{NaA}}$ as the partition coefficient of the sodium ion-pair and the term $\mathrm{pK}_{\mathrm{NaA}}$ defined by

$p K_{\mathrm{NaA}}=-\log \frac{\left[\mathrm{Na}^{+}\right]_{w}\left[\mathrm{~A}^{-}\right]_{w}}{[\mathrm{NaA}]_{w}}$

In principle a $\log \mathrm{P}_{\mathrm{app}}-\mathrm{pNa}$ profile can be obtained by analogy with a $\log \mathrm{P}_{\mathrm{app}}-\mathrm{pH}$ profile. It is very unlikely that $\mathrm{NaA}$ will be found in the aqueous phase because the high concentration of $\mathrm{Na}^{+}$needed cannot be reached. This means that only the equivalent of Eq̣n. 8, viz.

$\log \mathrm{P}_{\mathrm{app}}=\log \mathrm{P}_{\mathrm{NaA}}-\mathrm{pNa}+\mathrm{pK} \mathrm{NaA}_{\mathrm{NaA}}$

can be found. Plotting $\log \mathrm{P}_{\mathrm{app}}$ against the $\mathrm{pNa}$ results in a straight line with a slope of -1 .

\section{Materials and methods}

The chemical formulae of the 4-hydroxycoumarin derivatives and their sources are summarized in Table l. The purity of the compounds was checked by means of high-performance liquid chromatography (see below) and by means of thin-layer

\section{TABLE 1}

CHEMICAL FORMULAE AND SOURCES OF THE 4-HYDROXYCOUMARIN DERIVATIVES<smiles>O=C1CC(O)c2ccccc2O1</smiles>

A

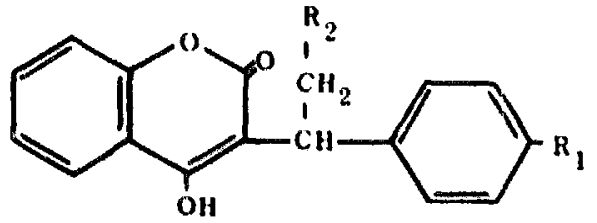

B<smiles>O=C(Oc1ccccc1)C(=[V])[C]([O-])c1c(O)c2ccccc2oc1=O</smiles>

C

\begin{tabular}{llll}
\hline No. & Compound & Formula & Source \\
\hline 1 & 4-hydroxycoumarin & A & Marfarin \\
2 & acenocoumarin & $\mathrm{B} \mathrm{R}_{1}=\mathrm{H} \mathrm{R}_{2}=-\mathrm{CO}-\mathrm{CH}_{3}$ & ACF \\
3 & phenprocoumon & $\mathrm{B} \mathrm{R}_{1}=\mathrm{NO}_{2} \mathrm{R}_{2}=-\mathrm{CO}-\mathrm{CH}_{3}$ & $\mathrm{CG}$ \\
4 & $\mathrm{~B} \mathrm{R}_{1}=-\mathrm{H} \mathrm{R}_{2}=-\mathrm{CH}_{3}$ & $\mathrm{HR}$ \\
5 & ethylbiscoumaretate & $\mathrm{C} \mathrm{R}=-\mathrm{CO}-\mathrm{OC}_{2} \mathrm{H}_{5}$ & CG \\
6 & coumetarol & $\mathrm{C} \mathrm{R}=-\mathrm{CH}_{2}-\mathrm{OCH}_{3}$ & ACF
\end{tabular}

The compounds were supplied by Ciba-Geigy (CG; Arnhem, The Netherlands), Hoffmann-La Roche (HK; Mijdrecht. The Netherlands), A.C.F. Chemiefarma (ACF; Maarssen, The Netherlands) or purchased from Merck (M; Darmstadt, G.F.R.). 
chromatography (van der Giesen and Janssen, 1982). In all cases only one compound preved to be present. The melting points of the 4-hydroxy compounds used were: compound 1: $205-207^{\circ} \mathrm{C}$ (lit. $206^{\circ} \mathrm{C}$. Handbook of Tables for Organic Compound Identification, 1967); compound 3: $199-200^{\circ} \mathrm{C}$ (lit. 196-199 ${ }^{\circ} \mathrm{C}$. Merck

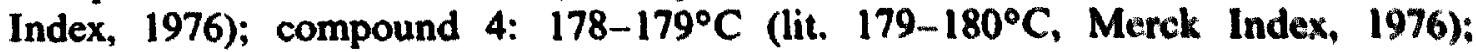
compound 5: $177-179^{\circ} \mathrm{C}$ (lit. $177-182^{\circ} \mathrm{C}$, Merck Index, 1976) and compound 6: $161^{\circ} \mathrm{C}$ (lit. $156-157^{\circ} \mathrm{C}$, Merck Index, 1976). Compound 2 was of British Pharmacopoeia quality. Octanol (Merck, Darmstadt, G.F.R.) was purified by successive washings with an equal volume of $4 \mathrm{M} \mathrm{NaOH}, 2 \mathrm{M} \mathrm{H}_{2} \mathrm{SO}_{4}$ and $1 \mathrm{M} \mathrm{Na}_{2} \mathrm{CO}_{3}$. Finally the octanol was washed repeatedly with water until the water phase reacted neutral. The buffers used for the determination of the $\mathrm{pH}$-dependent partitioning had an ionic strength, $I$, of about 0.1 and were composed as follows: pH 1.1-3.0 HCl-KCl (Biochemists' Handbook, 1961); pH 3.0-4.0 citric acid-sodium citrate (Biochemists' Handbook, 1961); pH 4.0-5.8 HAc-NaAc (Biochemists' Handbook. 1961); pH 5.8-8.0 $\mathrm{NaH}_{2} \mathrm{PO}_{4}-\mathrm{NaOH}$; pH 8.2-9.2 $\mathrm{H}_{3} \mathrm{BO}_{3}-\mathrm{NaOH} ;$ oH 9.0-11.0 $\mathrm{NaHCO}_{3}-\mathrm{Na}_{2} \mathrm{CO}_{3}$ (Biochemists' Handbook, 1961) or glycine- $\mathrm{NaOH}$ (Biochemists' Handbook, 1961). The buffers used for the determination of the $\mathrm{Na}^{+}$-dependent partitioning were $0.025 \mathrm{M}$, to which $\mathrm{NaCl}$ was added to achieve one of the desired $\mathrm{Na}^{+}$concentrations. The octanol and buffer solutions were mutually saturated. The samples were dissolved in the phase in which they were most soluble. The distribution coefficients were determined by gently shaking $5 \mathrm{ml}$ octanol with $10 \mathrm{ml}$ buffer solution for $2 \mathrm{~h}$. Equilibration was generally reached within half an hour. A shake-waterbath (Precision Scientific, Chicago, U.S.A.) provided with a thermostat $\left(25^{\circ} \mathrm{C}\right)$ was used. After letting the mixture stand for a few minutes the $\mathrm{pH}$ was measured in the water phase and the phases were centrifuged for $10 \mathrm{~min}$ at 5000 rpm. For the $\mathrm{pNa}$ profiles the $\mathrm{pNa}$ was measured too. The $\mathrm{pH}$ was measured using a digital $\mathrm{pH}$ meter, model P!IM 62 with a combined glass-reference $\mathrm{pH}$ electrode, type GK 2401C (Radiometer, Copenhagen, Denmark). The pNa was measured using the same pH meter equipped with a sodium-sensitive glass electrode, type $\mathrm{G} 502 \mathrm{Na}$ and : calomel reference electrode, type K 401 (Radiometer).

The concentrations of the 4-hydroxycoumarin derivatives were determined in the water phase when $\log P_{\text {app }}>1$, in the octanol phase when $\log P_{\text {app }}<-1$, in both phases when $-1<\log P_{\mathrm{app}}<1$. When the concentration in only one phase was determined experimentally the concentration in the other phase was obtained by calculation. The concentrations were determined using a high-performance liquid chromatograph consisting of an autosampler, model WISP, a high-pressure pump. model 6000 and a UV detector type 440 with a $313 \mathrm{~nm}$ filter (Waters Associates, Etten-Leur, The Netherlands) combined with a flat-bed recorder, model BD 8 (Kipp, Delft, The Netherlands). A prepacked reversed-phase column Lichrosorb 10 RP $18,25 \mathrm{~cm} \times 4.6 \mathrm{~mm}$ (Chrompack, Middelburg, The Netherlands) was used and $1 \%$ acetic acid in methanol-water mixtures as mobile phase $(1.5 \mathrm{ml} / \mathrm{min})$. Methanol concentrations ranged from 30 to $70 \%(v / v)$ and were chosen to achieve $\log k^{\prime}$ values of about 0.5. Depending on the concentration, $25-100 \mu \mathrm{l}$ of the water phase was injected. Always $5 \mu 1$ of the cctanol phase was injected because larger volumes influenced the retention times and could therefore make quantitative determinations 
inaccurate. The concentrations were calculated from the chromatograms from peak height measurements. Compounds 5 and 6 were found to decompose in the aqueous phase. The decomposition products are unknuwn. Compound 5 and 6 formed one and two decomposition products, respectively. Samples from both the aqueous and the organic phase which were analyzed as quickly as possible after shaking produced only minor extra peaks in the chromatograms, which means that compounds 5 and 6 hardly decompose during shaking and that reasonably accurate partition coefficients can be obtained. However, the concentrations of the decomposition products in the aqueous phase inereased with time and since it was impossible to analyze all the samples immediately after shaking we decided to sum the heights of the peaks in the chromatograms of the aqueous phase.

When the analysis is carried out within $24 \mathrm{~h}$ after shaking - and it always was in our case-me the relative error in the concentration of compounds 5 and 6 in the aqueous phase is smaller than $5 \%$.

The $\mathrm{pk}_{\mathrm{a}}$ values were determined by potentiometric titration or by spectrophotometry, as proposed by Albert and Serjeant (1971). An ionic strength of about 0.1 was achieved by the addition of potassium chloride.

\section{Results and discussion}

\section{pH profiles}

The distribution coefficients, $P_{\text {ip. }}$., were determined using the method described above. In Fig. $2 \log \mathrm{P}_{\mathrm{app}}$ is plotted against $\mathrm{pH}$ for compounds 1-4. At relatively low pH straight lines with zero slopes have been drawn, according to Eqn. 7. As an example the calculated slope value for warfarin from the experimental points is $-0.02( \pm 0.01)^{\prime}$. There is no doubt that at low $\mathrm{pH}, \log \mathrm{P}_{\mathrm{app}}$ is independent of $\mathrm{pH}$. Also at relatively high $\mathrm{pH} \log \mathrm{P}_{\text {app }}$ is independent of $\mathrm{pH}$ in accordance with theory. At intermediate $\mathrm{pH}$ values, straight lines with a slope value of -1 have been drawn, according to Eqn. 8. In Table 2 the values of the slopes are given as calculated from the experimental points of the straight lines obtained when $\log P_{a p p}$ is plotted against $\mathrm{pH}$. It is clear from this table that in the pH region mentioned Eqn. 8 is valid. When the lines with slope values of -1 are extrapolated, points of intersection with the extrapolated zero slope lines are obtained. The $\mathrm{pH}$ values of the intersections at low

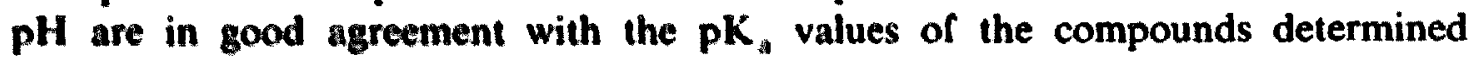
independently (see Table 2).

In a given solvent system the height of the plateau of the graphs at low pH is only dependent on the lipophilicity of the compounds and is equal to $\log \mathbf{P}_{\mathrm{HA}}$ and is therefore characteristic for the compound under study. The $\log P_{\mathrm{HA}}$ values (the average of $\log \mathrm{P}_{\mathrm{app}}$ values at $\mathrm{pH}<\mathrm{pK}-1.5$ ) are also given in Table 2 . However, the height of the plateau at high $\mathrm{pH}$ is dependent on the kind of counterion, on the counterion concentration and on the lipophilicity of the ion-fair formed (see later).

\footnotetext{
The standard deviation is given in parentheses.
} 


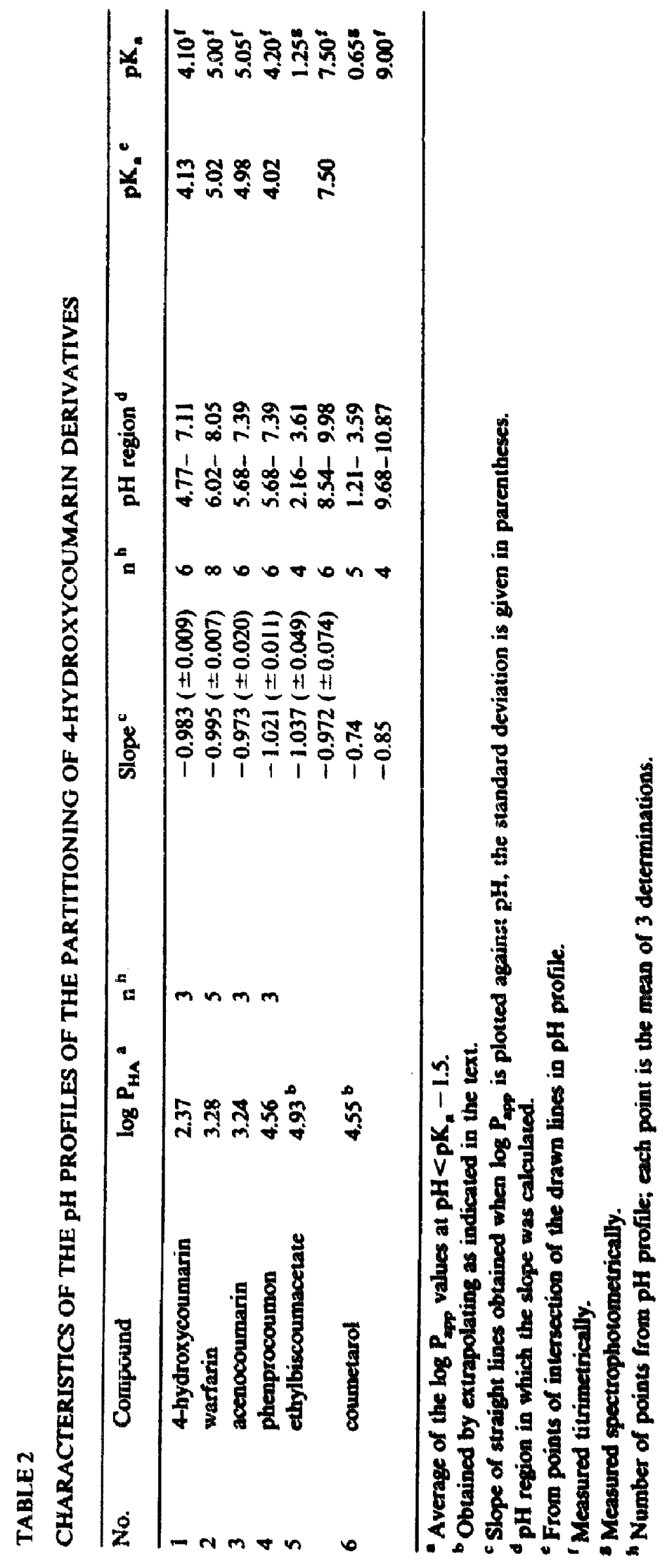




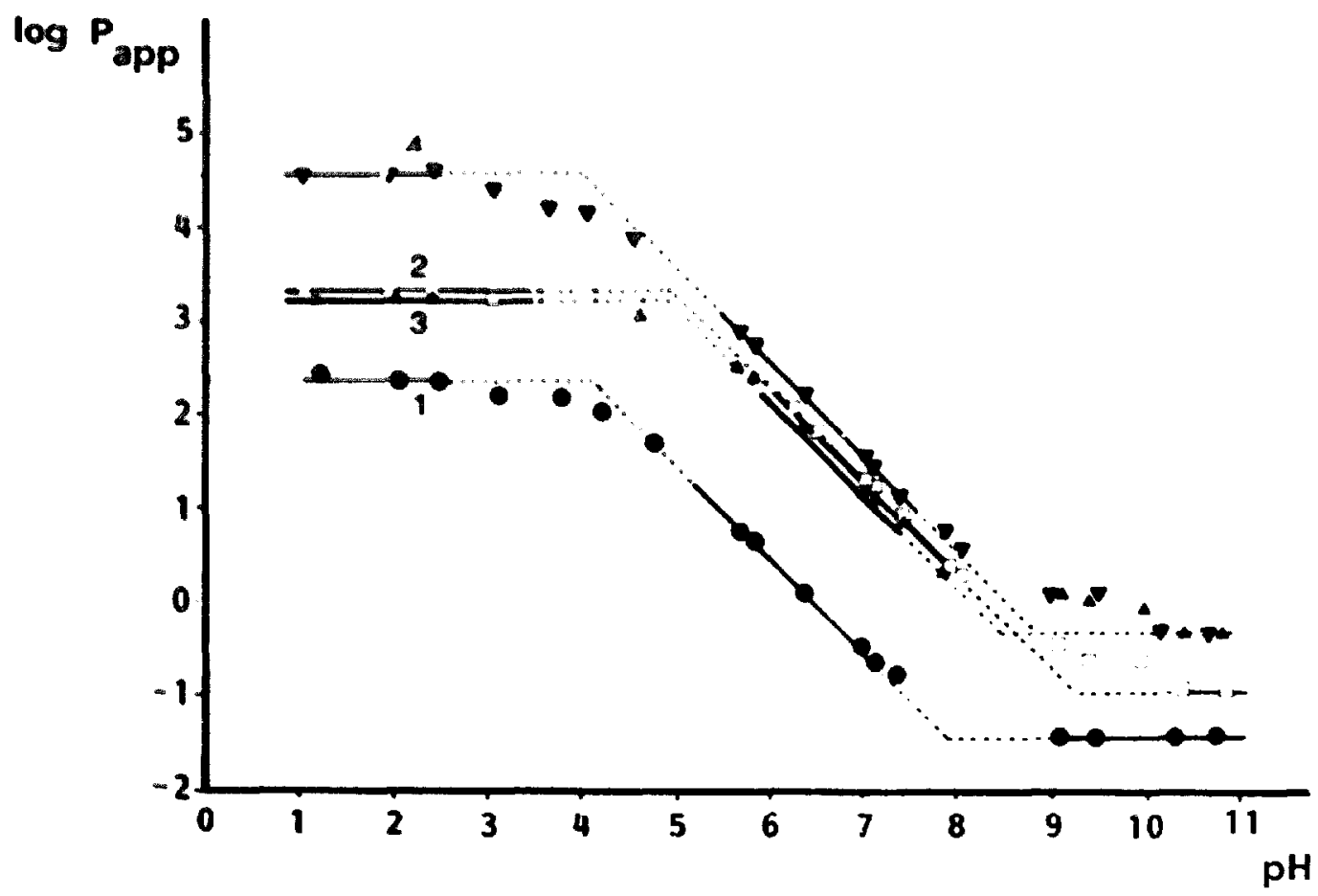

Fig. 2. Log $P_{\text {app }}-\mathrm{pH}$ profiles of monobasic 4-hydroxycoumarin derivatives. 1: 4-hydroxycoumarin; 2: warfarin; 3: acenocoumarin; 4: phenprocoumon. The points are the mean of 3 determinations. The lines have been drawn with slopes of -1 and 0 . The dashed lines are the extrapolated parts of the drawn lines.

The $\log \mathrm{P}_{\mathrm{app}}$ corresponding to the intersections at high $\mathrm{pH}$ is therefore a conditional constant.

At pHs around the pK. Eqns. 7 and 8 are not valid; Gien Eqn. 5 must be used to describe the $\mathrm{pH}$ profile. To prove the validity of this equation we calculated the log $P_{\text {app }}$ values of 4-hydroxycoumarin in the $\mathrm{pH}$ region 1.25-7.11 using Eqn. 5. A value of 2.37 was taken for $\log P$ and for the $p K_{a}$ a value of 4.13 . The standard error of estimate of $\log P_{\text {app }}$ turned out to be $0.044(n=12)$, which means that the $\log$ $P_{a p p}-p H$ profile found experimentally is in good agreement with theory.

For dibasic acids the $\log \mathrm{P}_{\text {app }}-\mathrm{pH}$ profile is more complicated because multiple ionization steps might occur. Depending on $\mathrm{pH}$, the species $\mathrm{H}_{2} \mathrm{~A}, \mathrm{HA}^{-}$and $\mathrm{A}^{2-}$ may be found in the aqueous phase. In the organic phase, $\mathrm{H}_{2} \mathrm{~A}, \mathrm{NaHA}$ and in principle $\mathrm{Na}_{2} \mathrm{~A}$ may occur. In Fig 3 the results are shown for the ciibasic compou ids 5 and 6 when $\log \mathrm{P}_{\text {app }}$ is plotted against $\mathrm{pH}$. The various characteristic parts have been denoted as I, II, III and IV to facilitate discussion. The $\mathrm{pK}_{\mathrm{a}}$ values will be called $\mathrm{pK}_{\mathrm{a}, 1}$ and $\mathrm{pK}_{\mathrm{a}, 2}$.

In part II around $\mathrm{pH} 2.5$, a straight line with a slope value of -1 has been drawn for compound 5. The exact slope value is given in Table 2. It will be clear that the distribution process is described here as predicted by Eqn. 8. In contrast to the situation described for compounds 1-4, the constant level at low pH, describing the distribution of $\mathrm{H}_{2} \mathrm{~A}$, could not be reached here, due to the relative low $\mathrm{pK}$ a,1 value (see Table 2). For compound 5 the dotted line which describes part I in Fig. 3 is a 


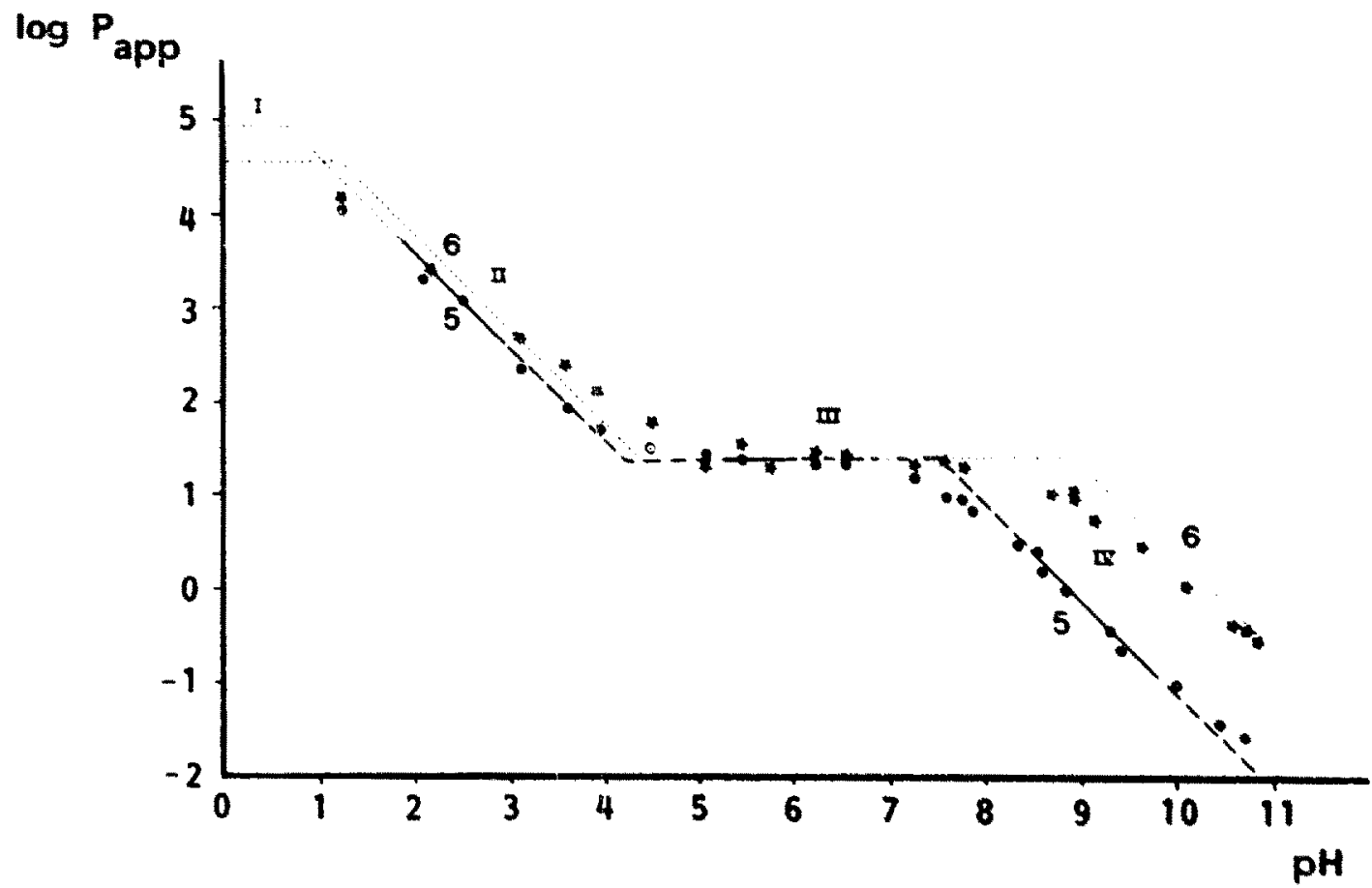

Fig. 3. $\log \mathrm{P}_{\mathrm{app}}-\mathrm{pH}$ profiles of dibasic 4-hydroxycoumarin derivatives. 5: ethylbiscoumacetate: 6: coumetarol. The points are the mean of 3 determinations. The lines have been drawn with slopes of -1 and 0 . The dashed lines are the extrapolated parts of the drawn lines. The dotted lines are drawn as expected theoretically, taking the known $\mathrm{pk}$, values into account.

theoretical one, i.e. the straight line with slope -1 was extrapolated to the point $\mathrm{pH}=\mathrm{pK}_{\mathrm{a}, \mathrm{l}}$ and from this point a zero slope line was drawn.

In a small $\mathrm{pH}$ region at intermediate $\mathrm{pH}$, indicated by $1 \mathrm{ll}$ in Fig. 3. $\log \mathrm{Papp}_{\mathrm{p}}$ is independent of $\mathrm{pH}$. In this region only partioning of $\mathrm{HA}^{-}$occurs and the $\log \mathrm{P}_{\text {app }}$ value depends on the kind of counterion, on the counterion concentration and on the lipophilicity of the ion-pair formed; a process occurs here analogous to that described for compounds $1-4$ at high pH. As long as only $\mathrm{HA}^{--}$is present in the aqueous phase, $\log \mathrm{P}_{\text {app }}$ can be described in the same way as Eqn. 12. viz.

$\log P_{\text {app }}=\log P_{\mathrm{NaHA}}-\mathrm{pNa}+\mathrm{pK} \mathrm{NaHA}_{\mathrm{Na}}$

When $\mathrm{pNa}$ is constant, $\log \mathrm{P}_{\mathrm{app}}$ must be constant too. Part IV describes the $\mathrm{pH}$ region where $\mathrm{HA}^{-}$dissociates into $\mathrm{A}^{2-}$, whereas in the organic phase $\mathrm{NaHA}$ will still be four.d. This part of the $\mathrm{pH}$ profile is given by

$\log \mathrm{P}_{\mathrm{app}}=\log \mathrm{P}_{\mathrm{NaHA}}-\mathrm{pNa}+\mathrm{pK}_{\mathrm{NaHA}}-\mathrm{pK} \mathrm{Ka}, 2_{2}-\mathrm{pH}$

So, as long as $\mathrm{pNa}$ is constant, $\log \mathrm{P}_{\mathrm{app}}$ against $\mathrm{pH}$ will result in a straight line with slope -1 . It should be noted that in the $\mathrm{pH}$ profile the point of intersection of the straight lines extrapolated according to Eqns. 13 and 14 corresponds to $\mathbf{p H}=\mathbf{p K}_{\mathrm{a.2}}$. Table 2 shows that these predictions have been confirmed experimentally especially 
for compound 5. The results for compound 6 are not in full agreement with theory, probably because some decomposition has occurred. The theoretical graph for compound 6 is given by the dotted line and is based on the known $\mathrm{pK}_{\mathrm{a}}$ values.

From the results described so far it will be clear that $\log \mathrm{P}$ values of ionizable compounds can only be calculated from $\mathrm{pK}_{\mathrm{a}}$ and $\log \mathrm{P}_{\mathrm{app}}$ values if the $\log \mathrm{P}_{\mathrm{app}}$ values have been obtained at pHs where ion-pair extraction did not occur. Unger (1980) also made a remark to this effect. The method proposed by Ezumi and Kubcta (1980) for determining simultaneously $P$ and $K_{a}$ values from $P_{\text {app }}$ values at pHs around the $\mathrm{pK}_{\mathrm{a}}$ using Eqn. 9 does not make it possible to check whether ion-pair extraction occurs; this method therefore can yield erroneous values for $\mathbf{P}$ and $K_{\text {a }}$. Possible ion-pair extraction can be examined by establishing whettier Eqn. 8 is valid for the compound in the solvent system under study. The $\mathrm{pK}$, values can be obtained from pH profiles, as shown in Figs. 2 and 3. This can be interesting when it is not possible to determine $\mathrm{pK}_{\mathrm{a}}$ values by spectrophotometry or by potentiometric titration.

Terada et al. (1981) did not consider the problem of electroneutrality in a two-phase system ant thay calculated a value for the partition coefficient of the anion and of two different ion-pairs of 2,4-dinitrophenol. Unfortunately, these authors did not give a statistical analysis of their data, but we assume that if the given value of the partition coefficient of the anion $\left(3.5 \times 10^{-3}\right)$ is indeed significantly larger than 0 , st.:all amounts of cationic impurities might be involved.

\section{Comparison of calculated and experimental values of $\log P_{H A}$}

Table 3 gives the $\log P_{\mathrm{HA}}$ values found experimentally. It is of interest to investigate if these values can be calculated using the system of the hydrophobic fragmental constant of Rekker (Rekker, 1977; Rekker and De Kort. 1979). The results are presented in Table 3 . The calculation of $\log P_{H A}$ values according to the rules given by Rekker gives far too iow values except in the case of coumarin, the

TABLE 3

EXPERIMENTAL AND CALCULATED lor PMa VALUES

\begin{tabular}{|c|c|c|c|c|}
\hline Compound & $\log P_{\text {enp }}$ & $\log P_{\text {calc }}$ & $\log P_{\text {calc }} b$ & $\overline{\log } \overrightarrow{P_{\text {culc }}}$ \\
\hline coumarin & 1.43 & 1.37 & & \\
\hline 4hydroxycoumarn & 2.97 & n 37 & & \\
\hline warfarin & 3.28 & 2.45 & 3.94 & 3.49 \\
\hline acenocoumarin & 3.24 & 2.21 & 3.71 & 3.25 \\
\hline Phenprocoumus: & 4.36 & 4.09 & 5.59 & \\
\hline ethylbiscoumicetate & 4.93 & 1.69 & 4.68 & \\
\hline coumetarol & 4.55 & 1.35 & 4.34 & \\
\hline
\end{tabular}

Calculated by means of the hydrophobic fragmental constant system using $f$ values from column IV of Table 2 of Rekker and De Kort (1979).

"Calculated with $\mathrm{t}$ value of 4-hydroxycoumarin skeleton of $2.37-f(\mathrm{H})=2.188$.

c As b, but now hemiketal structure is assumed (Valente and Trager, 1978). 
calculated value of which is in reasonable agreement with the value found experimentally. Re-calculating the $\log \mathbf{P}_{\mathrm{HA}}$ values for 5 compounds, starting with the experinentally found value for 4-hydroxycoumarin, gives considerably higher values, but these are not yet in accordance with the experimentally found values. The correct value of $\log P$ for acenocounarol is found only if a hemiketal structure is assumed for this compound (Valente and Trager, 1978). If, however, warfarin is assumed to have a hemiketal structure, the calculated value of $\log P$ still deviates from the experimental value.

Many examples are known for which the f-sysiem yields good agreement between calculated and experimentally obtained $\log P$ values. It should be pointed out that the experimentally found $\log \mathbf{P}_{\mathrm{HA}}$ values for compounds $1-4$ and $\log \mathbf{P}_{\mathrm{HA}}$ values obtained by extrapolating for compounds 5 and 6 correlate very well with the $R_{M_{w}}$ values in a reversed-phase thin-layer chromatographic system in which oleyl alcohol is used as lipid phase (van der Giesen and Janssen, 1982), as shown in Eqn. 15'

$\log P_{\mathrm{HA}}=0.859( \pm 0.034) \mathrm{R}_{\mathrm{M}_{\mathrm{w}}}+2.187( \pm 0.074)$

$\mathrm{n}=6 \quad r^{2}=0.9938 \quad \mathrm{~s}=0.088 \quad F=664$

$0.787<$ slope $^{b}<0.931 \quad 2.030<$ intercept $^{2}<2.344$

When we restrict our discussion to the experimentally found $\log P$ values, it becomes clear that the lipophilic behaviour of the 4-hydroxycoumarins is quite unusual. Introducing a hydroxyl group in position 4 of the coumarin skeleton increases the lipophilicity enormously, whereas a considerable decrease was expected regardless of whether the hydroxyl group should be considered as being aromatic or aliphatic. Intrculucing a p-nitro group into warfarin, which results in acenocoumarol, does not give the expected clear decrease in the lipophilicity. Also the difference between the $\log P$ values of warfarin and phenprocoumon (one carbonyl group) is smaller than expected. Finally the differences between, for instance, the $\log P$ values of warfarin and ethylbiscoumacetate and between warfarin and coumetarol are much larger than expected. The large discrepancy between calculated and experimentally obtained log $P$ values suggests that the structures of the coumarins in the aqueous phase or in the organic phase or in both are significantly different from the structures that coumarins are generally assumed to have. It might be that dimerization takes place in the organic phase via hydrogen bond formation. However, this possibility seems to be ruled out because we did not observe any concentration dependence of the $\mathrm{P}$ values. Complications may also be caused by the tautomeric behaviour of the 4-hydroxycoumarins. This type of compound may occur in a keto and in an enol form. The exact concentration of a given tautomeric form will be governed by the tautomeric equilibrium constant defined here as $K_{T}=[$ keto] $/$ [enol].

\footnotetext{
The standard deviation is given in parentheses; $n=$ number of compounds; $r=$ correlation coefficient; $s=$ standard error of estin:ate or $s_{y, x} ; F=$ value of the F-test of significance.

: $90 \%$ confidence interval.
} 
It is well known that such a $\mathbf{K}_{\mathbf{T}}$ depends strongly on the medium (Albert, 1968). This means that $K_{T}$ is different for the aqueous and for the organic phase ( $K_{T, w}$ and $K_{T, 0}$, respectively). It can easily be demunstrated that $K_{T, 0}$ and $K_{T, w}$ are linked: $\mathbf{K}_{\mathrm{T}, 0}=\left(\mathbf{P}_{\text {keto }} / \mathbf{P}_{\text {enol }}\right) \cdot \mathbf{K}_{\mathrm{T}, \mathrm{w}}$. In this expression $\mathbf{P}_{\text {keto }}$ and $\mathbf{P}_{\text {enol }}$ represent the partition coefficient of the keto and encl form, respectively. This means that the keto and enol form must have a different lipophilicity. This bas direct consequences for the measured partition coefficient, which is now given by $\mathbf{P}=\left(\mathbf{P}_{\text {keto }} \cdot \mathbf{K}_{\text {T.w }}+\right.$ $\left.\mathbf{P}_{\text {enol }}\right) /\left(\mathbf{K}_{\mathrm{T}, \mathrm{w}}+1\right)$. The value of $\mathbf{P}$ lies somewhere between the extreme values $\mathbf{P}_{\text {keto }}$ and $P_{\text {enol }}$, and will depend on $K_{\mathrm{T}}$. It is reasonable to assume that the changes in the $P$ values of both the keto and enol form, due to chemical modification, will follow the usual pattern. However, chemical modification will also cause a change in $K_{T}$, which gives complications. We suggest that such phenomena may explain the unusual lipophilic behaviour of 4-hydroxycoumarins. Unfortunately it is very difficult to study the tautomerism of these compounds (Elguero et al., 1976) and no data for tautomeric constants are available. In addition one should realize that for the series of compounds in this study a third tautomeric form having an acid proton on position 3 is possible as well (O'Neal et al., 1982). Another possible explanation for the very high $\log P$ values of the dicoumol compounds 5 and 6 is that intramolecular hydrogen bond formation occurs between the carbonyl and the enolic hydroxyl groups of the adjacent ring systems (Hutchinson and Tomlinson, 1969); if this occurs, then these polar groups will be less available for interaction with the water molecules, and the lipophilicity will increase. The role of intramolecular hydrogen bond formation has been mentioned already in literature (Hansch and Leo, 1979a).

\section{pNa profiles}

The $\mathrm{pNa}$-dependent partitioning of compounds $1-4$ has been studied at $\mathrm{pH}=10.0$ and of compounds 5 and 6 at $\mathrm{pH}=6.0$. In Fig. 4 the results are given when $\log \mathrm{P}_{\text {app }}$ is plotted against $\mathrm{pNa}$. For the compounds $2-4$ straight lines with slope values very close to $-\|$ are found; the exact slope values are given in Table 4 . The validity of Eqn. 12 is evident, and provides proof for the ion-pair formation in the organic phase. For compounds 5 and 6 straight lines were obtained too. The slope values, however, deviate from -1 (see also Table 4). This is surprising especially since the $\log \mathrm{P}_{\mathrm{app}}-\mathrm{pH}$ profile of compound 5 is in full agreement with the theory. For the moment we do not have a sound explanation for this anomalous behaviour. In any case, these results suggest that ion-pair formation occurs in the organic phase for the dicoumol compounds too.

The slope value -0.507 found for compound 1 is in contradiction to Eqn. 12 . This value of -0.5 suggests a transfer of a $1: 2$ complex from the water phase to the organic phase. Since only a neutral complex can pass to the other phase, this would suggest the involvement of a complex with bruto formula $\mathrm{NaHA}_{2}$. However, the partitioning of such a complex should be $\mathrm{pH}$-dependent at high $\mathrm{pH}$ as well, but this in fact is not the case, see Fig. 2.

Another possible explanation for the slope value -0.507 might be a dimerization in the organic phase. However, dimerization was already excluded to occur, see 


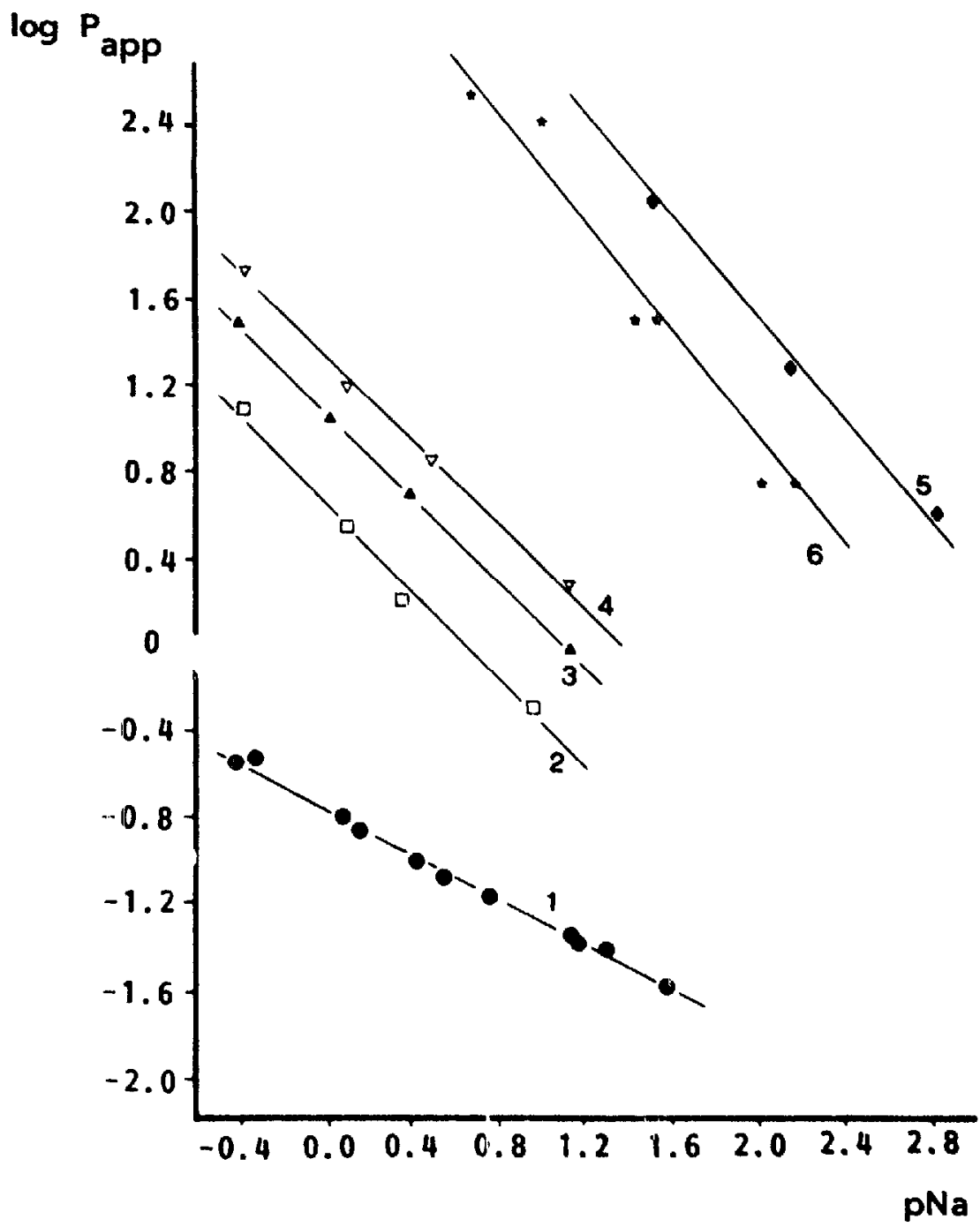

Fig. 4. $\log ; P_{\text {app }}-\mathrm{pNa}$ profiles of 4-hydroxycoumarin derivatives. 1: 4-hydroxycoumarin: 2: warfarin: 3 : acenoccumarin; 4: phenprocoumon; 5: ethylbiscoumacetate; 6: coumetarol. The points are the mean of 3 determinations. The drawn lines are calculated from experimental points using the least-squares method for linear regression, see also Table 4 . The values for compounds $1-4$ were obtained at $\mathrm{pH}=10.0$, for compotinds 5 and 6 at $\mathrm{pH}=6.0$.

above. We think that dissociation of the ion-pair in the organic phase as described by Johansson and Schill (1980) for the tetrabutylammonium ion-pair of octyl sulfate in 1-pentanol might offer an explanation for this effect. Partitioning of a weak acid at high pH including dissociation of the sodium ion-pair in the organic phase can be represented by Scheme $c$ in Fig. 1. The various equilibria in this scheme can be defined as follows. The dissociation constant of the ion-pair in the water phase $\mathbf{K}_{\mathrm{NaA}}$

$K_{\mathrm{NaA}}=\frac{\left[\mathrm{A}^{-}\right]_{w}\left[\mathrm{Na}^{+}\right]_{\mathrm{w}}}{[\mathrm{NaA}]_{\mathrm{w}}}$ 
TABLE 4

CHARACTERISTICS OF THE PNa PROFILES OF THE PARTITIONING OF 4HYDROXYCOUMARIN DERIVATIVES

\begin{tabular}{|c|c|c|c|c|c|c|c|}
\hline No. & Compound & Slope ${ }^{2}$ & $n^{b}$ & $\log P_{\text {NaA }} c$ & $\begin{array}{l}\log P_{H A} \\
-\log P_{\text {NaA }}\end{array}$ & $\log P_{\text {app }} d$ & $\begin{array}{l}\log P_{\mathrm{HA}} \\
-\log \mathrm{P}_{\mathrm{app}}\end{array}$ \\
\hline 1 & A-bydrexycoumarin & $-0.507( \pm 0.011)$ & 12 & & & -1.28 & 3.65 \\
\hline 2 & warfarin & $-1.002( \pm 0.072)$ & 4 & $>2.55$ & $<0.73$ & -0.38 & 3.66 \\
\hline 3 & acenocoumarin & $-0.970( \pm 0.023)$ & 4 & $>2.98$ & $<0.26$ & 0.08 & 3.16 \\
\hline 4 & phenprocoumon & $-0.966( \pm 0.041)$ & 4 & $>3.25$ & $<1.31$ & 0.38 & 4.22 \\
\hline 5 & ethylbiscoumucetale & -1.17 & 3 & & & & \\
\hline 6 & coumetarol & -1.22 & 6 & & & & \\
\hline
\end{tabular}

\footnotetext{
a Slope of the straight lines obtained when $\log \mathrm{P}_{\text {app }}$ is plotted against $\mathrm{pNa}$, the standard deviation is given in parentheses.

- Number of points from $\mathrm{pNa}$ profile, each point is the mean of 3 determinations.

- Obtained from extrapolating to Eqn. 12.

Experimental value under the conditions $\mathrm{pNa}=1$ and $\mathrm{pH}=10$.
}

The dissociation constant of the ion-pair in the octanol phase $\mathbf{K}_{\mathrm{NaA}_{0}}$

$$
K_{\mathrm{NaA}_{\mathrm{o}}}=\frac{\left[\mathrm{A}^{-}\right]_{0}\left[\mathrm{Na}^{+}\right]_{0}}{[\mathrm{NaA}]_{0}}
$$

The partition coefficient of the undissociated ion-pair $\mathbf{P}_{\text {NaA }}$

$$
P_{\mathrm{NaA}}=\frac{[\mathrm{NaA}]_{0}}{[\mathrm{NaA}]_{w}}
$$

Since sodium salts are normally completely dissociated in aqueous solutions, the distribution coefficient for this situation can be represented by:

$P_{\text {app }}=\frac{[\mathrm{NaA}]_{0}+\left[\mathrm{A}^{-1}\right]_{\mathrm{o}}}{\left[\mathrm{A}^{-}\right]_{\mathrm{w}}}$

To express $P_{\text {app }}$ in the measurable quantities $\left[\mathrm{Na}^{+}\right]_{w}$ and $\left[A^{-}\right]_{w}$, it is convenient to use an extraction constant (Schill, 1978) $\mathrm{K}_{\mathrm{ex}}$

$K_{\text {ex }}=\frac{[\mathrm{NaA}]_{0}}{\left[\mathrm{Na}^{+}\right]_{w}\left[\mathrm{~A}^{-}\right]_{w}}=\frac{\mathbf{P}_{\mathrm{NaA}}}{\mathbf{K}_{\mathrm{NaA}}}$

Combining Eqns. 17 and 20 results in:

$$
\left[A^{-}\right]_{0}\left[\mathrm{Na}^{+}\right]_{0}=\mathrm{K}_{e x} \cdot \mathrm{K}_{\mathrm{NaA}_{0}}\left[\mathrm{Na}^{+}\right]_{w}\left[\mathrm{~A}^{-}\right]_{w}
$$


If $\mathrm{NaA}$ is the only ion-pair that passes to the organic phase, then $\left[\mathrm{Na}^{+}\right]_{0}=\left[\mathrm{A}^{*}\right]_{0}$ and hence Eqn. 22 is valid

$\left[A^{-}\right]_{0}=\left(\mathbf{K}_{e x} \cdot \mathbf{K}_{\mathrm{NaA}_{0}}\left[\mathrm{Na}^{+}\right]_{\mathrm{w}}\left[\mathbf{A}^{-}\right]_{\mathrm{w}}\right)^{1 / 2}$

Combining of Eans. 19, 20 and 22 results in:

$\mathbf{P}_{\text {app }}=\left[\mathrm{Na}^{+}\right]_{w}\left(\mathbf{K}_{\mathrm{ex}}+\left(\mathrm{K}_{\mathrm{ex}} \cdot \mathrm{K}_{\mathrm{NaA}_{0}} \cdot\left[\mathrm{Na}^{+}\right]_{\mathrm{w}}^{-1}\left[\mathrm{~A}^{-}\right]_{w}^{-1}\right)^{1 / 2}\right)$

If $\mathrm{K}_{\mathrm{NaA}_{0}}$ is zero, then $\mathrm{P}_{\mathrm{app}}=\left[\mathrm{Na}^{+}\right]_{\mathrm{w}} \cdot \mathrm{K}_{\text {ex }}$, which is equivalent with Eqn. 12. Now $P_{a p p}$ has been expressed in terms of $\left[\mathrm{Na}^{+}\right]_{w}$ and $\left[A^{-}\right]_{w}$. Eqn. 23 can be written as

$\mathbf{P}_{\text {app }}\left[\mathrm{Na}^{+}\right]_{w}^{-1}=\mathbf{K}_{\mathrm{ex}}+\left(\mathbf{K}_{\mathrm{ex}} \cdot \mathbf{K}_{\mathrm{NaA}_{0}} \cdot\left[\mathrm{Na}^{+}\right]_{\mathrm{w}}^{-1} \cdot\left[\mathrm{A}^{-}\right]_{\mathrm{w}}^{-1}\right)^{1 / 2}$

If $\mathbf{P}_{\text {app }} \cdot\left[\mathrm{Na}^{+}\right]_{w}^{-1}$ is plotted against $\left(\left[\mathrm{Na}^{+}\right]_{w}\left[\mathrm{~A}^{-}\right]_{w}\right)^{-1 / 2}$, then a straight line is obtained with an intercept $K_{e x}$ and slope value of $\left(K_{e x} \cdot K_{\mathrm{NaA}_{0}}\right)^{1 / 2}$. Doing this for 4-hydroxycoumarin does indeed result in a straight line with a slope value of 3.698 $( \pm 0.18) \cdot 10^{-3}(n=8 ; F=976)$ and since this value is significantly larger than zero, this proves the validity of the model presented here. This method does not give reliable values for $\mathrm{K}_{e: \mathrm{x}}$ of 4 -hydroxycoumarin due to the wide-ranging extrapolation that is needed $\left(K_{e x}=3.16 ! \pm 11.1\right) \cdot 10^{-3}$ was found). The slope of -0.5 in the log $P_{a p p}-p N a$ profile can now be explained by assuming that $K_{e x}$ in Eqn. 23 or 24 is much smaller than $\mathrm{K}_{\mathrm{ex}} \cdot \mathrm{K}_{\mathrm{NaA}_{0}} \cdot\left[\mathrm{Na}^{+}\right]_{w}^{-1}\left[\mathrm{~A}_{\mathrm{i}}^{-}\right]_{w}^{-1}$. The logarithmic form of Eqn. 23 then becomes:

$P_{a p p}=0.5\left(\log K_{e x}-\mathrm{pK}_{\mathrm{NaA}_{0}}\right)-0.5\left(\mathrm{pNa}-\log \left[\mathrm{A}^{-}\right]_{w}\right)$

Plotting $\log i_{\text {app }}$ against $\mathrm{pNa}-\log \left[\mathrm{A}^{-}\right]_{w}$ will result in a straight line with a slope valte of -0.5 . Applying this to 4-hydroxycoumarin gives a straight line with a slope of $(.504( \pm 0.016)$. The conclusion is that Eqn. 25 is valid owing to the considerable dissociation of the sodium ion-pair of 4-hydroxycoumarin in the octanol phase.

It is remarkable that when $\log P_{a p p}$ of 4-hydroxycoumarin is plotted against $\mathrm{pNa}$ or against pNa $+\log \left[\mathrm{A}^{-}\right]_{*}$ nearly the same slope value is found in both cases. The reason for this is that at relatively small values of $P_{\text {app }}$ and/or at relatively small values of the volume ratio organic phase-aqueous phase, $\left(\mathrm{A}^{-}\right]_{w}$ can be considered as a constant.

Estimation of $\log \boldsymbol{P}_{\mathrm{NaA}}$ from $\log \boldsymbol{P}_{a p p}-p$ Na profiles

From Fig. 4 it can be seen that at least up to a $\mathrm{pNa}$ value of -0.4 the $\mathrm{pNa}$ profiles of compounds 2-4 are linear with a slope of -1 . This means that the $\mathrm{pK}_{\mathrm{NaA}}$ of these compounds is lower than -1.9 , so the minimum value of $\log P_{\mathrm{NaA}}$ can be estimated by extrapolating $\log \mathrm{P}_{\text {app }}$ until $\mathrm{pNa}=-1.9$ according to Eqn. 12. The obtained values are given in Table 4. This table also shows the differences between 
$\log \mathrm{P}_{\mathrm{HA}}$ and $\log \mathrm{P}_{\mathrm{NaA}}$. One comes to the remarkable conclusicn that the lipophilicity of the undissociated ion-pair is not so very different from the lipophilicity of the undissociated acid HA. The results presented here, provided they have a general validity and also hold for biomembranes, suggest that the fact that ionized molecules are poorly adsorbed from the gastrointestinal tract is not due to the low lipophilicity of the ion-pair but to the low concentrations of (appropriate) counterions in the aqueous environment.

For compound 3 the smallest difference between $\log \mathrm{P}_{\mathrm{HA}}$ and $\log \mathrm{P}_{\mathrm{NaA}}$ has been found. If the hydrophobic fragmental constant of hydrogen $\mathrm{f}(\mathrm{H})$ is 0.18 (Rekker and De Kort, 1979), then $\mathrm{f}(\mathrm{Na})$ should be at least $-0.26+0.18=-0.08$.

\section{$\log P_{H A}, \log P_{\text {app }}$ and $\log P_{N a A}$ in QSAR}

In QSAR studies it would be interesting to use $\log P_{\mathrm{NaA}}$ as hydrophobic parameter. However, it will generally be impossible to deteimine $\log P_{\mathrm{NaA}}$, because the counterion concentration cannot be chosen high enough to suppress the dissociation of the ion-pair in the aqueous phase. For applications in QSAR Hansch and Leo (1979b) have proposed the use of a hydrophobic parameter of ionized molecules, obtained at standardized conditions by measuring the distribution coefficients of the protolytes at a $\mathrm{pH}$ of the aqueous phase more than $4 \mathrm{pH}$ units away from the pK. (that is, above the $\mathrm{pK}_{\mathrm{a}}$ of acids and below the $\mathrm{pK}_{\mathrm{a}}$ of bases) and at a small inorganic counterion concentration of $0.1 \mathrm{M}$. This could be achieved by using $0.1 \mathrm{M}$ $\mathrm{NaOH}$ or $0.1 \mathrm{M} \mathrm{HCl}$ as aqueous phase. For acids this means: $P_{\text {app }}$ values obtained at very high $\mathrm{pH}$ at a $\mathrm{pNa}$ of 1 . It is obvious from Fig. 2 and Eqn. 8 that $\log P_{\text {app }}$ at, for instance, $\mathrm{pH}=6$ depends on both $\log \mathrm{P}_{\mathrm{HA}}$ and $\mathrm{pK}_{\mathrm{a}}$. Analogous to this, $\log \mathrm{P}_{\mathrm{app}}$ depends on both $\log \mathbf{P}_{\mathrm{NaA}}$ and $\mathrm{pK} \mathrm{NaA}_{\mathrm{NaA}}$ at high $\mathrm{pH}$ where $\mathrm{P}_{\mathrm{app}}$ is independent of $\mathrm{pH}$, see Fig. 4 and Eqn. 12. It therefore seems inadvisable to use such a $\log P_{\text {app }}$ value as a hydrophobic parameter, since its value is determined by constants of hydrophobic and electrostatic origin. To illustrate this point for the 4-hydroxycoumarins such standardized $\log P_{\text {app }}$ values are given in Table 4. In addition the differences are given between these $\log P_{\text {app }}$ values and the $\log P_{H A}$ values. It is clear from this table that complete dissociation of the 4-hydroxycoumarins does not lower the distribution coefficient to the same extent for the several compounds. Testa and MursetRossetti (1978) made similar observations for a series of antihistamines. A constant difference between the $\log P_{\text {npp }}$ values under the standardized conditions mentioned above and the $\log P_{H A}$ values can only be expected if the dissociation constants of the various salts are the same.

It has become clear from this study that it is not possible to obtain an f-value (Rekker and De Kort, 1979) or a $\pi$-value (Hansch and Leo, 1979b) of carboxylate, protonated amine and quaternary ammonium using the standardized method proposed by Hansch and Leo, because such values are also dependent on the dissociation constants of the salts of which the ionized group is a fragment. It should be stressed that better insight into the lipophilic behaviour of protolytes can only be obtained from both $\log P_{a p p}-p N a$ profiles (or, in general, from $\log P_{a p p}-p X$ profiles, when $X$ is the counterion) and $\log P_{\text {app }}-p H$ profiles, but not from $\log \mathrm{P}_{\text {app }}-\mathrm{pH}$ profiles only. 


\section{Acknowledgements}

We are grateful to Mrs. Ineke Bakker for technical assistance and to Professor Dr. C.J. de Blaey and Professor Dr. R.F. Rekker for critically reading the manuscript.

\section{References}

Albert. A. Heterocyclic Chemistry, 2nd Edn., The Athlone Press, University of London, 1968, pp. 372-375.

Albert, A. and Serjeant, E.P.. The Determination of Ionization Constants, Chapmann and Hall, London. 1971.

Bicchemists" Handbook, Cyril Long (Ed.), Spon., London, 1961, pp. 29-41.

Colaizzi. J.L. and Klink, P.R., pH-partition behavior of tetracyclines. J. Pharm. Sci., 58 (1969) 1184- 1189.

Dearden, J.C. and George, E., Effect of lipophilicity of ionisable drugs on deviations from expected pH-partition behaviour. J. Pharm. Pharmacol., 30 (1978) 49P.

Elguero, J., Marzin, C., Katritzky. A.R. and Linda, P.. The tautomerism of heterocycles. In Suppl. 1 of Advances in Heterocyclic Chemistry, Katritsky, A.R. and Boulton, A.J. (Eds.), Academic Press, New York-San Francisco-London, 1976, p. 118.

Ezumi, K. and Kubota, T.. Simultaneous determination of acid dissociation constants and true partition coefficients by analyses of the apparent partition coefficients. 1. Chem. Pharm. Bull., 28 (1980) 85-91.

Giesen. van der, W.F.. and Janssera, L.H.M., Adsorption behaviour of several supports in reversed-phase thin-layer chromatography as demonstrated by the determination of relative partition coefficients of some 4-hydroxycoumarin derivatives. J. Chromatogr., 237 (1982) 199-213.

Handbook of Tables for Organic Identification, 3rd Edn., Rappoport, Z. (Ed.). The Chemical Rubber Co., Cleveland, $\mathrm{CH}, 1967$.

Hansch. C. and Leo, A., Substituent Constants for Correlation Analysis in Chemistry and Biology, John Wiley and Sons, New York-Chichester-Brisbane-Toronto, 1979a, p. 16; 1979b, p. 38.

Hansch. C., Muir. R.M., Fujita, T., Maloney, P.P., Geiger. F. and Strejch, M.. The correlation of biological activity of plant growth regulators and chloromycetin derivatives with Hammett constants and partition coefficients. J. Am. Chem. Soc., 85 (1963) 2817-2824.

Hansch, C., Unger, S.H. and Forsythe. A.B., Strategy in drug design. Cluster analysis as an aid in the selection of substituents. J. Med. Chem., 16 (1973) 1217-1222.

Irwin, G.M., Kostenbauder, H.B.. Dittert, L.W., Staples, R., Misher, A. and Swintosky, J.V.. Enhancement of gastrointestinal absorption of a quaternary ammonium compound by trichloroacetate. J. Pharm. Sci., 58 (1969) 313-315.

Irwin, W.J. and $\mathrm{Li}$ Wan Po. A., The dependence of amitriptyline partition coefficients on lipid phase. Int. J. Pharm., 4 (1979) 47-56.

Johansson. I.M. and Schill, G., Extraction of octyl sulfate to l-pentanol. Acta Pharm. Suec.. 17 (1980) $112-129$.

Merck Index. 9th Edn., Windholz, M. (Ed.), Merck and Co., Rahway, NY, 1976.

Moser. P., Jakel, K., Krupp, P., Menasse, R. and Sallmann, A., Structure-activity relations of analogs of phenylbutazone. Eur. J. Med. Chem., 10 (1975) 613-617.

Murthy, K.S. and Zografi, G., Oil--water partitioning of chlorpromazine and other phenothiazine derivatives using dodecane and n-octunol. J. Pharm. Sci., 59 (1970) 1281-1285.

O'Neal, J.S., Schulman. S.G. Van der Giesen, W.F. and Roomer, A.C.J., Alkaline hydrolytic lability of some hyclroxy- and methoxycoumarins and related anticoagulants, submitted for publication.

Petit, G., le, Die pH-abhăngige 'Lipidlöslichkeit' von Arzneistoffen. Pharmazie, 32 (1977) 289-291.

Petit, G. le, Die pH-abhăngige Lipidloslichkeit von Arzneistoffen. Pharmazie, 35 (1980) 696-698.

Rekler, R.F., The Hydrophobic Fragmental Constant, Elsevier, Amsterdam-Oxford-New York, 1977.

Rekker, R.F. and Kort, H.M. de, The hydrophobic fragmental constant; an extension to a 1000 data point set, Eur. J. Med. Chem., 14 (1979) 479-488. 
Schaper, K.J., Gleichzeitige Bestimmung electronischer und lipophiler Merkmale [pKa, P(Ion), P(Neutral)] acider und basischer Verbindungen durch nicht-lineaire Regressions-Analyse pH-abhängiger Verteilungsmessungen. J. Chem. Res., (M) (1979) 4480-4493.

Sichill, G. Separation Methods for Drugs and Related Organic Compounds, Swedish Academy of Pharmaceutical Sciences, Stockholm, 1978.

Simith. R.N.. Hansch, C. and Ames, M.M., Selection of a reference partitioning system for drug design work. J. Tharm. Sci., 64 (1975) 599-606.

Terada, H., Kitagawa, K., Yoshikawa, Y. and Kametani, F., Partition and ion-pair partition of 2.4-dinitrophenol, an uncoupler of oxidative phosphorylation. Chem. Pharm. Bull., 29 (1981) 7-14.

Testa. B. and Murset-Rossetti, L., The partition coefficient of protonated antihistamines. Its calculation and interpretation in terms of hydrophobic fragmental constants. Helv. Chim. Acta, 61 (1978) 2530-2537.

Tsuji, A., Kubo, O., Miyamoto, E. and Yamana, T., Physicochemical properties of $\beta$-lactam antibiotics: oil-water distribution. J. Pharm. Sci., 66 (1977) 1675-1679.

Jnger, S.H., Consequences of the Hansch paradigm for the pharmaceutical industry. In Ariëns, E.J. (Ed.), Drug Design, Academic Press, New York, 1980, p. 109.

Unger, S.H. and Feuerman. T.F., Octanol-aqueous partition, distribution and ionization coefficients of lipophilic acids and their anions by reversed-phase high-performance liquid chromatography. $J$. Chromatogr., 176 (1979) 426-429.

Valente, E.J. and Trager, W.F., Anomalous chiroptical properties of warfarin and phenprocoumun. J. Med. Chem., 21 (1978) 141-143.

Vezin, W.R. and Florence, A.T., The determination of dissociation constants and partition coefficients of phenothiazine derivatives. Int. J. Pharm., 3 (1979) 231-237.

Wang, P.H. and Lien, E.J., Effects of different buffer species on partition coefficients of drugs used in quantitative structure-activity relationships. J. Pharm. Sci., 69 (1980) 662-668.

Wilting. J., Giesen, van der, W.F., and Janssen. L.H.M., The effect of chloride on the binding of warfarin to albumin as a function of pH. Biochem. Pharmacol., 30 (1981) 1025-1031.

Wilting, J., Giesen, van der, W.F., Janssen, L.H.M., Weideman, M.M., Otagiri, M. and Perrin, J.H., The effect of alhumin conformation on the binding of warfarin to human serum albumin. J. Biol. Chem., 225 (1980) 3032-3037.

Yalkowsky, S.H. and Morozowick, W., A physical chemical basis for the design of orally active prodrugs. In Arièns, E.J. (Ed.), Drug Design, Academic Press, New York, 1980, pp. 158-161.

Hutchingson, D.W. and Tomlinson. J.A. The structure of dicoumarol and related compounds, Tetrahedron. 25 (1969) 2531-2537. 